\title{
Hydraulic flood routing in an ephemeral channel: Wadi Mekerra, Algeria
}

\author{
M'hamed Atallah $^{1,2} \cdot$ Abdelkrim Hazzab $^{2} \cdot$ Abdelali Seddini $^{3} \cdot$ Abdellah Ghenaim $^{4}$. \\ Khaled Korichi ${ }^{2,5}$
}

Received: 22 September 2016/ Accepted: 5 October 2016/Published online: 24 October 2016

(c) Springer International Publishing Switzerland 2016

\begin{abstract}
Wadis are a vital source of water in most arid and semi-arid countries. Catastrophic flash floods occurring in wadis are a threat to many societies. The Wadi Mekerra basin in the North-West of Algeria represents one of these semi-arid regions the most affected by floods and has been always one of the main concerns of managers in Sidi Bel Abbes province. In this work, we present the main climatic and hydromorphometric features of Wadi Mekerra watershed. We discuss the main factors that cause flooding in the studied catchment. A hydraulic model based on the RungeKutta Discontinuous Galerkin (RKDG) finite element scheme and a limited (existing) field data was applied and compared with measured flow data. The objective was to assess whether a reliable hydraulic flood routing model of a Wadi in a semi-arid region could be developed, with limited cross section data supplemented by topographic map information. A comparison between the measured and simulated results shows that the model used is appropriate
\end{abstract}

M'hamed Atallah

mhamed.atallah.dz@gmail.com

1 Department of Science and Technology, El-Bayadh university Center, El-Bayadh, Algeria

2 Modeling and Computational Methods Laboratory, Saïda University, P.O. Box 138, En Nasr, Saïda, Algeria

3 Department of Hydraulics, Faculty of Engineering, Tlemcen University, P.O. Box 230, 13000 Tlemcen, Algeria

4 Design Engineering Laboratory (LGECO, ERESA), INSA Strasbourg Graduate School of Science and Technology, 24 bd de la Victoire, 67084 Strasbourg, France

5 Hydraulics Department, Faculty of Technology, University of Djillali Liabes, Sidi Bel Abbes, P.O. Box 89, 22000 Sidi Bel Abbes, Algeria for determining the flood hydrograph at the outlet of the watercourse.

Keywords Semi-arid regions - Ephemeral watercourse Wadi Mekerra · Flood - Saint-Venant equations · Runge-Kutta discontinuous Galerkin

\section{Introduction}

In arid and semi-arid regions people live mostly along the Wadi banks (Wadi is the Arabic word for ephemeral water courses in the arid regions) and flood plains, depending for their survival on occasional surface water and permanent groundwater resources for domestic and agricultural activities. Infrequent surface water and flood occurrences may cause natural hazards that may threaten property and life. Floods are infrequent, but extremely damaging, and the threat from floods to lives and infrastructure is increasing due to urban development (Şen 2008).

Algeria experienced several flood disasters. According to civil protection, 485 (1/3 of 1541) municipalities are recognized as flood-prone areas at different risk levels (Sardou et al. 2016). In October 1994, floods across the country resulted in 60 fatalities and left hundreds missing during 10 days of bad weather (Meddi and Toumi 2015). The flood that affected Bab El Oued district (Algiers) on 10 November 2001 caused one of the unique and worst scenario that resulted in 750 fatalities, 115 missing, left some 30,000 people homeless, in addition to pure economic damages of over 250 million euro. The flood occurred on 1 October 2008, in Ghardaia (south of Algeria), resulted in more than 100 deaths, 86 wounded, 4 missing and 756 damaged disaster victim families (Yamani et al. 2016). The material damage estimated at almost 40 million euro. 
Floods in Mekerra Basin, northwestern Algeria affect more than 200,000 residents in this region. From 1986 to 2007, floods have caused extensive damage (10 dead and 929 homeless families).

The analysis performed by Sardou et al. (2016), of historical flood events that occurred in northwestern Algeria per watershed reveals the concentration of flooding in specific areas such as the major rivers. The authors showed that the total number of floods occurring during autumn with damage is more than $52.54 \%$, with 16.95 and $13.56 \%$ during September and November, respectively. During October, $22.03 \%$ of the annual total events corresponds to dramatic floods. This value can be explained by the intense thunderstorms resulting from heavy rainfall that occurs over short periods causing flash floods particularly in the beginning of autumn (Price et al. 2011). During autumn, floods are usually of torrential type. They cause a large number of victims, mainly due to the high population density in prone flooding areas near torrential and nonpermanent streams (Llasat et al. 2010; Sardou et al. 2016).

Future flood impacts can be limited through risk reduction measures such as changes in land uses and building codes, selective relocation of vulnerable assets, improved flood defenses, emergency preparedness and insurance (Hanson et al. 2011). Moreover, flood inundation models play a central role in the evaluation, selection and in some cases the implementation of these measures (Ernst et al. 2010; Merz et al. 2010; Schubert and Sanders 2012). Flood routing is an important component of floodplain management studies which is recognized as a procedure required in order to determine the hydrograph at one point on a stream from the known hydrograph at an upstream point (Chow 1959; McKay et al. 1996; Perumal et al. 2007). The need to model flood behavior adequately arises from (a) knowing the timing and the magnitude of expected flooding early enough to facilitate safe evacuation of people and livestock (b) assessing the environmental impacts of river regulation (Wilson 1990) and dam failure (Blackburn and Hicks 2002) (c) designing flood prevention systems like spillways, culverts and diversion canals (Viessman et al. 1989; Smithers and Caldecott 1995).

Clearly flood routing is an important component of floodplain management studies, and this requires appropriate decision support systems, including modelling tools. Modelling methods have been widely used over 60 years for a variety of purposes, but almost all modelling tools have been primarily developed for humid area applications. Arid and semi-arid areas have particular challenges that have received little attention.

Flood routing procedures may be classified as either hydrological or hydraulic (Singh 1988, 1989; Abbott and Refsgaard 1996; Choudhury et al. 2002). A survey of these models is presented by Lettenmaier and Wood (1993) and is contained in the book of Abbott and Refsgaard (1996). Traditionally, hydrologic flood routing models are conceptual models, based on mass conservation and an empirical approximation of momentum effects (Hicks 1996; Shaw et al. 2010). Hydraulic routing models use both continuity and momentum equations to describe unsteady, non-uniform flow in a flow system. It is based on Saint-Venant equations, a continuity equation which describe the balance between input, storage and output in a section of river, and a momentum equation which relates the change in momentum to the applied forces (Liggett and Cunge 1975; Bathurst 1988; Arora et al. 2001). The first attempt to numerically simulate the one-dimensional Saint-Venant equations for flood routing problems was made by Stoker et al. (1953) and Isaacson et al. (1954). In 1961, Preissmann (1961) provided the famous four point box scheme. Since then, a variety of numerical techniques have been used to solve flood routing problems. These include the finite difference, the finite volume and the finite-element models. Many of these standard numerical models are discussed or described by Chaudhry (2008); LeVeque (2002); Hervouet (2007).

In this paper, a one-dimensional model based on SaintVenant equations was solved by a Runge-Kutta Discontinuous Galerkin (RKDG) finite element scheme. We apply the method for simulation of flood propagation in Wadi Mekerra. The reach used for the investigation was the Wadi Mekerra section from Sidi Ali Benyoub gauging station to Sidi Bel Abbes gauging station over $52 \mathrm{~km}$ of a routing distance. This contribution aims to identify potential risk areas, the wave magnitude and the time required to alert threatened agglomerations.

The remainder of the paper is organized as follows. "Study area" presents a global description and general information about the study site, flow regime and the floods occurred in Wadi Mekerra. "Model description" presents governing equations of Saint-Venant model including numerical methods in which RKDG scheme are briefly presented. In "Simulations and results" we apply the numerical model to the 1983 summer flood and 1995 autumn flood on the Wadi Mekerra. We end by "Conclusion".

\section{Study area}

\section{General informations}

The Wadi Mekerra basin belongs to the big basin of Macta which is located at the North-West of Algeria (Fig. 1). It occupies a surface area of approximately $3000 \mathrm{~km}^{2}$ and a perimeter length of approximately $391.3 \mathrm{~km}$. This basin is drained by the Wadi Mekerra which develops a talweg of $144 \mathrm{~km}$ length. The two main Wadis, the Wadi Mekkera in 


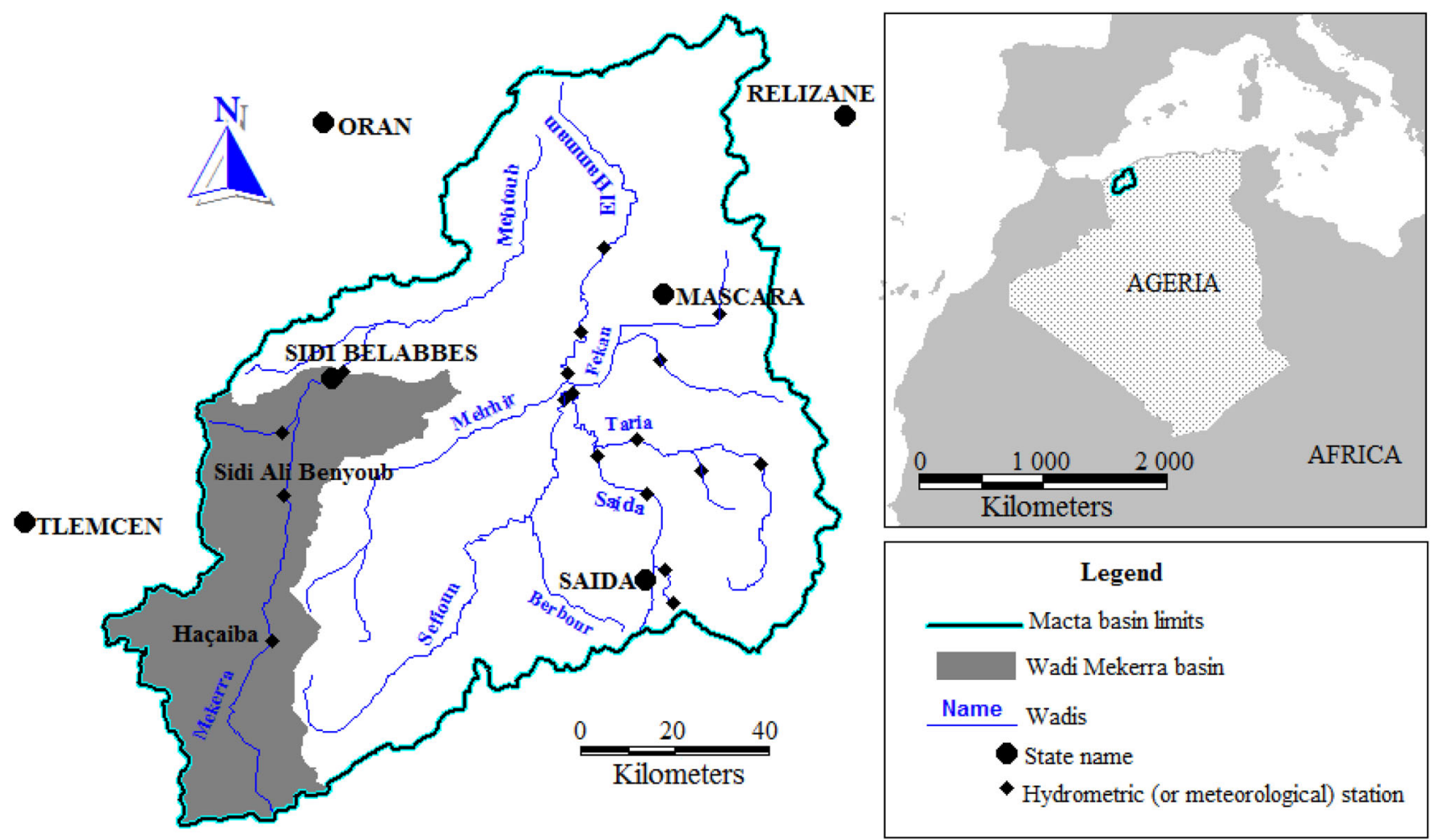

Fig. 1 Location of the Wadi Mekerra basin

the West and Wadi El Hammam in the East meet near the Mediterranean Sea coast to form the Macta basin (Fig. 1).

The catchment area has an elongated form and it is oriented from South to North. The maximum and minimum altitudes are respectively 1715 and $437 \mathrm{~m} .50 \%$ of the area of the basin is located in an altitude above the $1000 \mathrm{~m}$, which explains the torrential streams character. The Wadi Mekerra crosses two quite distinct relief zones:

- The mountainous solid mass of Daya in the South with an altitude which varies between $1600 \mathrm{~m}$ and $800 \mathrm{~m}$. The mean slope of the Wadi until Sidi Ali Ben Youb is about 1 to $1.5 \%$.

- The Wadi emerges downstream from the town of Boukhanafis in the alluvial plain of Sidi Bel Abbes with a very weak slope $(0.3-0.8 \%)$ generating relatively low flow velocities.

The Mekerra watershed is divided into three sub-basins (Haçaïba, Sidi Ali Benyoub and Sidi Bel Abbes sub-basin). Each one has a gauging station. Table 1 summarizes the main hydromorphometric characteristics of each sub-basin.

\section{Vegetation}

Like most West Algerian regions, vegetation cover in Wadi Mekerra basin is largely degraded due to agricultural expansion, fires and overgrazing.
In Wadi Mekerra basin, the irrigation areas are located mainly in Sidi Bel Abbes and Sfisef plains. The dominated crops are the truck farming and fruit orchards. Forests scrub and bush occupies almost the entire mountains band located in the upper Mekerra. About $20 \%$ of the watershed is covered by forests, mainly found in mountain areas located between Haçaïba and Mouley Slissen and can extent up to Sidi Ali Benyoub as well as in the hilly areas uncultivable in the peripheral parts of the basin.

Between Ras El Ma and Haçaiiba, the large areas covered by Alfa in the past have been replaced in recent decades by cereal crops. Between Sidi Ali Benyoub and Sidi Bel Abbes, in Mekerra plain, the cereal crops are generally associated with orchards or groves, sometimes irrigated (vines).

\section{Geology}

According to the geologic map (Fig. 2), the humus calcareous soils are predominant. This calcareous crust is permeable and plays an important role in the flood attenuation phenomenon. The northern part of the basin is covered with a mosaic of alluvial, calcareous and calcic soils. The torrential flow reveals the parent rock in a few places.

In the geological cup achieved following the SouthNorth direction that crosses the Wadi Mekerra on its length 
Table 1 Characteristics of the Mekerra sub-basins

\begin{tabular}{lllll}
\hline Features & Unit & Haçaiba station & Sidi Ali Benyoub station & Sidi Bel Abbes station \\
\hline Basin area & $\mathrm{Km}^{2}$ & 957 & 1890 & 3000 \\
Compactness index & - & 1.15 & 1.29 & 1.43 \\
Maximum height value & $\mathrm{m}$ & 1440 & 1715 & 1714 \\
Minimum height value & $\mathrm{m}$ & 925 & 635 & 437 \\
Roche slope index & $\%$ & 0.099 & 0.0936 & 0.0913 \\
Wadi's length & $\mathrm{Km}$ & 54 & 92 & 144 \\
Drainage density & - & 0.06 & 0.050 & 0.02 \\
Torentiallity & - & 0.20 & 31.25 & 6.86 \\
Time of concentration & $\mathrm{h}$ & 6.369 & 10.560 & 13.448 \\
\hline
\end{tabular}

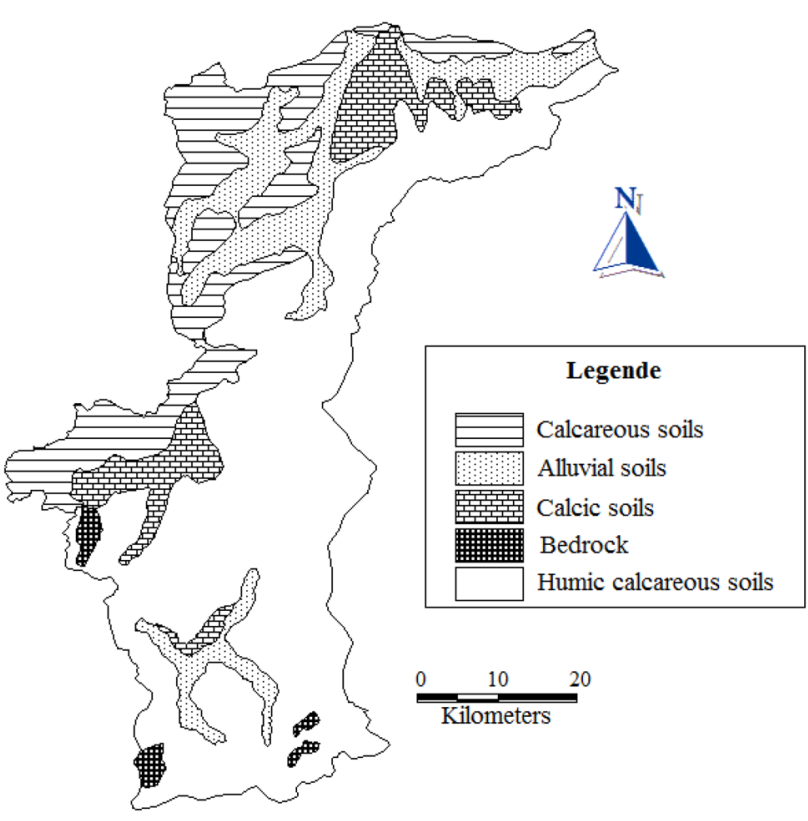

Fig. 2 Geologic map of Wadi Mekerra basin

it appears three faults directed from the South to the centre of the catchment area.

\section{Climate}

The climate is semi-arid Mediterranean characterized by a wet and dry seasons. The ombrothermic diagram (Fig. 3) for Sidi Bel Abbes station for the period 1948-2005 shows that the dry period starts from May until September while the cold and rainy period extends from the beginning of October until the end of April. $70 \%$ of the annual precipitation is observed in winter and spring. The Mean annual precipitation is $338 \mathrm{~mm}$ in Sidi Bel Abbes and the mean annual temperature is $16.2{ }^{\circ} \mathrm{C}$.

The study area is characterized by a slight wind with an average speed of $2.58 \mathrm{~m} / \mathrm{s}$. The prevailing winds are those from the North-West. The sirocco (south wind, hot and loaded with sand) is blowing about 15 days per year during the months of July and August

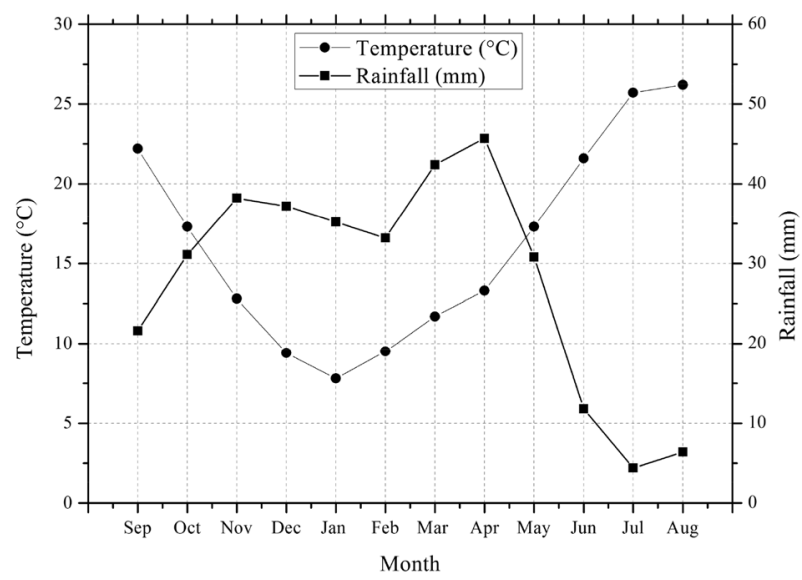

Fig. 3 Ombrothermic diagram at Sidi Bel Abbes station

In our region the relative humidity decreases from north to the south during the winter. It reaches relatively high values especially in mountainous areas. The mean annual value is about $69.5 \%$ in Sidi Bel Abbes.

\section{Flow regime of the Wadi Mekerra}

Depending on the degree of temporality, rivers and streams can be classified either as perennial (continuous flow) or temporary (seasonal flow). The latter are subdivided according to their dry period condition: intermittent rivers form chains of lotic features (isolated pools) as flow disappears but surface water is still present, and ephemeral rivers form dry stream beds as the water disappears (Uys and O'keeffe 1997; Argyroudi et al. 2009). Matthews (1988) regarded intermittent streams as those which flow $20-80 \%$ of the time, and ephemeral streams as those which flow $<20 \%$ of the time.

The flow regime of the Wadi Mekerra has been studied from the daily river discharge at Sidi Bel Abbes station. The chronological study of the daily discharge in Wadi Mekerra over 59 years (i.e. form 1942 to 2001), have been shown that the Wadi Mekerra was an ephem-eral river between 1942 and 1997 and thereafter became an 
intermittent river until 1999, with an average daily flow rate of $73 \%$ in 1999. Thereafter, it became an ephemeral river. From 1942 to 2001, that the average number of days with no flow went up and reached 328 days per year $(90 \%$ of the year). Therefore, the Wadi flow just 37 days per year (10\% of the year). Wadi Mekerra can be thus considered as an ephemeral river.

The study of the interannual variation in discharges in the studied basin (Fig. 4) shows a high discharge fluctuation from one year to another. From 1942 to 2001, the Wadi Mekerra passed by two long dry periods. The first extends over nine (9) years; from 1952 to 1962 where the mean annual discharge in this period was about $0.221 \mathrm{~m}^{3} / \mathrm{s}$ (the driest year was 1956 where the mean annual discharge was $0.039 \mathrm{~m}^{3} / \mathrm{s}$ ). The second period lasted seventeen (17) years; from 1968 to 1985 with mean annual discharge about $0.141 \mathrm{~m}^{3} / \mathrm{s}$. The driest year in this second period was $1978\left(0.022 \mathrm{~m}^{3} / \mathrm{s}\right)$.

\section{Floods in Wadi Mekerra}

Floods in Wadi Mekerra affect more than 200,000 residents in this region. From the Southern limit to the Northern limit of the basin, Wadi Mekerra passes through Redjem Demouche (the beginning or the source of the Wadi), Ras El Ma, Haçaiiba, Moulay Slissen, Sidi Ali Benyoub, Tabia, Boukhanefis, Sidi Khaled, Sidi Lahcen and Sidi Bel Abbes towns (Atallah and Hazzab 2013). Table 2 summarizes the major floods occurred between 1986-2007 that caused flooding in the main localities situated in Wadi Mekerra basin.

The main factors that cause flooding in the mekerra basin are: (1) An elongated basin shape, (2) A reduced time of concentration, (3) Storms and heavy rainfall in the upper

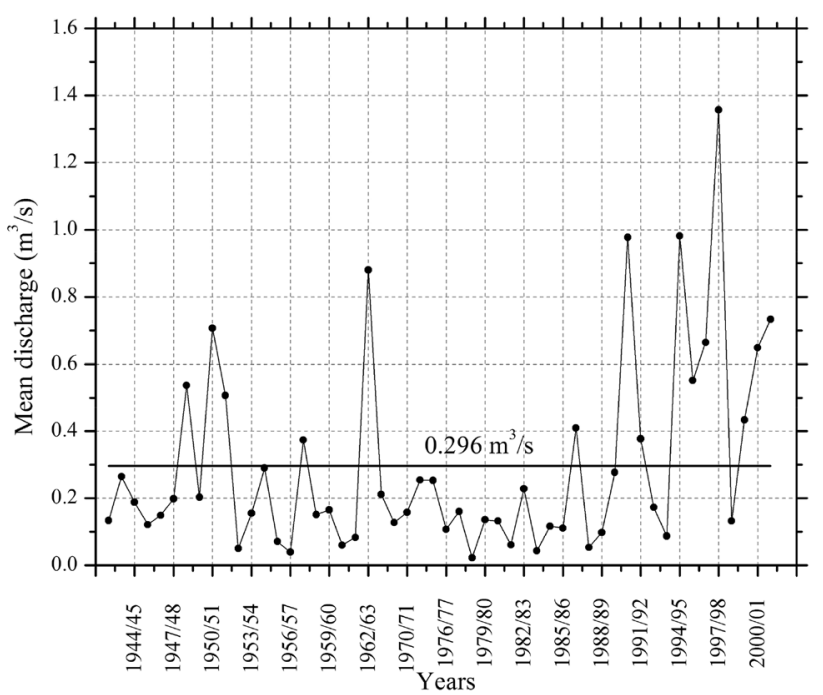

Fig. 4 Variation of mean annual discharge of Wadi Mekerra at Sidi Bel Abbes (1942-2001)
Mekerra, (4) The section of the Wadi become more narrow just downstream of Sidi Lahcen town, (5) The Wadi crosssection is reduced by the sediment transported and deposited during floods and the riparian vegetation cover increased in the Wadi, (6) Meandering and (7) Unplanned urbanization in the banks of the Wadi.

The floods in the semi-arid regions like the Mekerra basin are sporadic and ephemeral. Commonly, flood flows move down the channel network as a flood wave, moving over a bed that is either initially dry or has a small initial flow (Şen 2008). Hydrographs are typically characterized by extremely rapid rise times, of as little as $20-30 \mathrm{~min}$ and a slowly descent, more regularized, in phase of fall (i.e. the maximum intensity of the storm is generally observed at the beginning of this one).

Although most rainfall in Wadi Mekerra basin normally comes in the winter and spring, they have a low water discharges. While autumn has lower rainfall rates in comparison with winter and spring but it gives an important runoff (Fig. 5). This runoff is the result of floods that characterize this season. It appears that the hydrologic response of Wadi Mekerra depend strongly on the rainfall intensity.

The floods are more frequent and stronger in autumn months than any other. The last 52 years of observation shows that over $57 \%$ of the maximum instantaneous flow discharges are recorded in autumn. Figure 6 shows the peak annual discharges of historic floods in Wadi Mekerra between 1942 and 2001. The annual instantaneous peak discharge values vary considerably from one year to another due to the irregularity of the annual rainfall intensity also influenced by the type of climate in our region (semi-arid). We also see an increase in the magnitude of flood between 1990 and 2001.

The statistical study conducted by Korichi and Hazzab (2012) using 34577 instantaneous discharges for the period (1942-2001), spread over the three gauging stations (Haçaiba, Sidi Ali Benyoub and Sidi Bel Abbes) show that the class of dominants discharges is that less than $10 \mathrm{~m}^{3} / \mathrm{s}$. While the high discharges (more than $200 \mathrm{~m}^{3} / \mathrm{s}$ ) represents only $0.01 \%$ (Table 3 ).

\section{Model description}

\section{Governing equations}

The mass and momentum conservation equations that form one-dimensional Saint-Venant equations are given, respectively, below (Henderson 1966):

$$
\frac{\partial A}{\partial t}+\frac{\partial Q}{\partial x}=0
$$


Table 2 Human losses related to flood events occurred in Wadi Mekerra basin (1986-2007)

\begin{tabular}{|c|c|c|c|}
\hline \multirow[t]{2}{*}{ Date } & \multirow[t]{2}{*}{ Location } & \multicolumn{2}{|c|}{ Number of sinister } \\
\hline & & Dead & Homeless families \\
\hline October 4, 1986 & Sidi Bel Abbes & 1 & 200 \\
\hline April 30, 1990 & Sidi Bel Abbes & 2 & 130 \\
\hline \multirow[t]{2}{*}{ September 29, 1994} & Sidi Bel Abbes & 2 & 22 \\
\hline & Sidi Bel Benyoub & 1 & - \\
\hline December 5, 1995 & Sidi Bel Abbes & - & 3 \\
\hline August 17, 1997 & Moulay Slissen & 1 & 34 \\
\hline September 27, 1997 & Sidi Bel Abbes & 1 & - \\
\hline December 13, 1997 & Sidi Bel Abbes & 1 & 5 \\
\hline July 27, 2000 & Ras El Ma & - & 100 \\
\hline \multirow[t]{4}{*}{ October 23,2000} & Sidi Bel Abbes & 1 & 7 \\
\hline & Sidi Lahcen & - & 50 \\
\hline & Boukhanefis & - & 31 \\
\hline & Sidi Khaled & - & 50 \\
\hline August 2002 & Throughout the province & - & 200 \\
\hline June 8, 2003 & Moulay Slissen & - & 10 \\
\hline \multirow[t]{3}{*}{ May 27, 2006} & Ras El Ma & - & 23 \\
\hline & Sidi Khaled & - & 9 \\
\hline & Boukhanefis & - & 5 \\
\hline April 2007 & Moulay Slissen & - & 50 \\
\hline
\end{tabular}

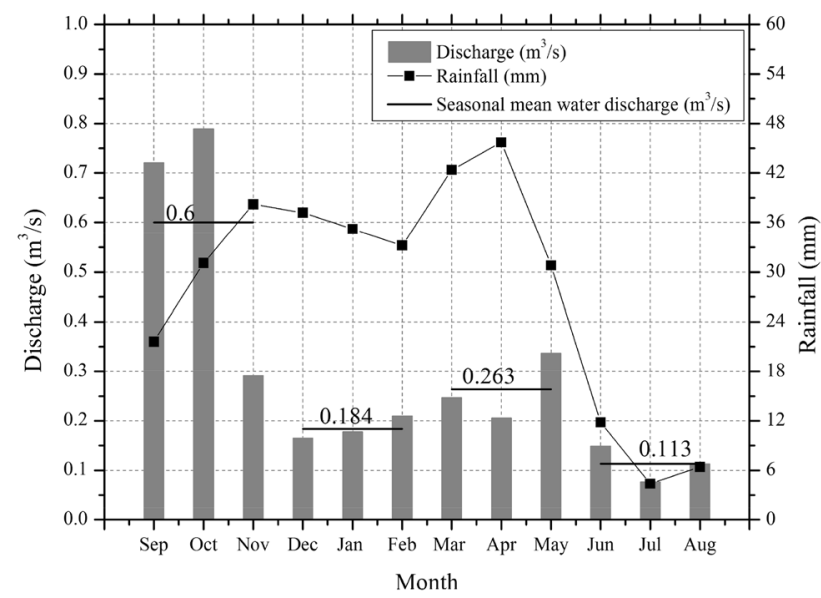

Fig. 5 Variability of mean monthly precipitation and water discharge in Wadi Mekerra at Sidi Bel Abbes (1942-2001)

$\frac{\partial Q}{\partial t}+\frac{\partial\left(Q^{2} / A\right)}{\partial x}=-g A \frac{\partial Z}{\partial x}-g A S_{f}$

In the equations described above, $A$ is the cross-sectional flow area, $Q$ is the flow rate, $g$ is the gravitational acceleration, $Z\left(=z_{b}+h\right)$ is the water surface elevation, $z_{b}$ is the channel bed elevation, $h$ is the water depth, $t$ is the temporal coordinate, $x$ is the longitudinal coordinate and $S_{f}$ is the friction slope and is given by the following equation

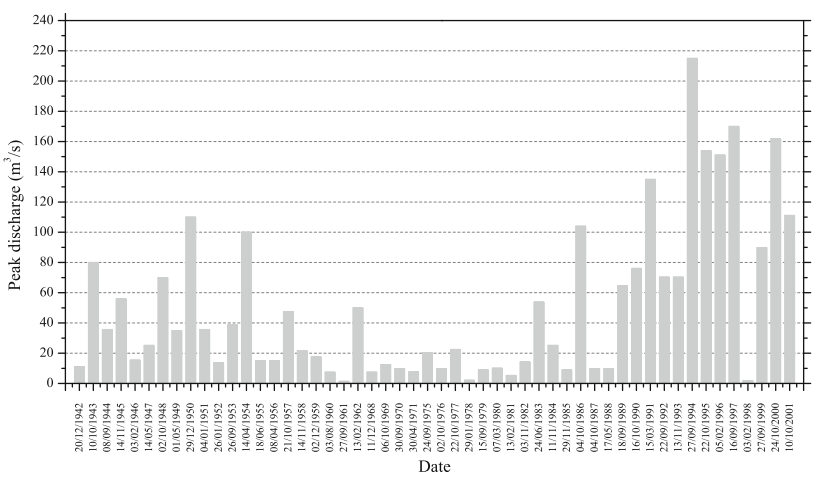

Fig. 6 Peak annual discharges of historic floods in Wadi Mekerra between 1942 and 2001

$S_{f}=\frac{n^{2} Q|Q|}{R^{4 / 3} A^{2}}$

where $n$ is the Manning's roughness coefficient and $R$ is the hydraulic radius (ratio of flow area to the wetted perimeter).

Equations 1 and 2 can be written in the following vector form as

$\frac{\partial \mathbf{U}}{\partial t}+\frac{\partial \mathbf{F}(\mathbf{U})}{\partial x}=\mathbf{S}(\mathbf{U})$ 
Table 3 Distribution in (\%) of floods in Wadi Mekerra between 1942 and 2001 (Korichi and Hazzab 2012)

\begin{tabular}{lllllr}
\hline Classes of discharges $\left(\mathrm{m}^{3} / \mathrm{s}\right)$ & $>200$ & $200-100$ & $100-50$ & $50-10$ & $<10$ \\
\hline Frequency $(\%)$ & 0.01 & 0.50 & 1.44 & 5.29 & 92.77 \\
\hline
\end{tabular}

where

$$
\mathbf{U}=\left(\begin{array}{c}
\mathbf{A} \\
\mathbf{Q}
\end{array}\right), \quad \mathbf{F}=\left(\begin{array}{c}
\mathbf{Q} \\
\frac{\mathbf{Q}^{2}}{\mathbf{A}}
\end{array}\right), \quad \mathrm{S}=\left(\begin{array}{c}
0 \\
\mathrm{gA} \frac{\partial}{\partial \mathbf{x}}-\mathrm{gAS}_{\mathrm{f}}
\end{array}\right)
$$

are respectively, the vectors of conserved variables, flux terms, and source terms. We put $E(x, t)=Q$ the flux term for the continuity equation and $G(x, t)=Q^{2} / A$ the flux function for the momentum equation.

\section{Discontinuous Galerkin implementation}

A brief description of the RKDG method for the SaintVenant equations is given below. Further details can be found in the book of Khan and Lai (2014). Figure 7 illustrates two elements and their boundaries in the DG framework with linear variation of the variables within an element. In the DG method the domain is discretized such that $\Omega_{j}=\left[x_{j}, x_{j+1}\right]$ with $j=1 ; 2 ; \ldots ; n_{e l}$, where $n_{e l}$ is the number of elements.

The implementation of the DG method includes the following steps

(i) The integral forms of the mass and momentum equations are:

$$
\begin{gathered}
\int_{x_{1}}^{x_{2}} N_{i} \frac{\partial \hat{A}}{\partial t} d x-\int_{x_{1}}^{x_{2}} \frac{\partial N_{i}}{\partial t} \hat{Q} d x+N_{i}\left(x_{2}\right) E\left(x_{2}, \mathrm{t}\right) \\
-N_{i}\left(x_{1}\right) E\left(x_{1}, \mathrm{t}\right)=0 \\
\int_{x_{1}}^{x_{2}} N_{i} \frac{\partial \hat{Q}}{\partial t} d x-\int_{x_{1}}^{x_{2}} \frac{\partial N_{i}}{\partial x} \frac{\hat{Q}^{2}}{\hat{A}} d x+N_{i}\left(x_{2}\right) G\left(x_{2}, t\right) \\
-N_{i}\left(x_{1}\right) G\left(x_{1}, t\right)=\int_{x_{1}}^{x_{2}} N_{i}\left(-g \hat{A} \frac{\partial \hat{Z}}{\partial x}-g \hat{h} \hat{S}_{f}\right) d x
\end{gathered}
$$

where $x_{1}$ and $x_{2}$ are the end coordinates of an element and $N_{i}(i=1,2)$ are linear test or weight functions

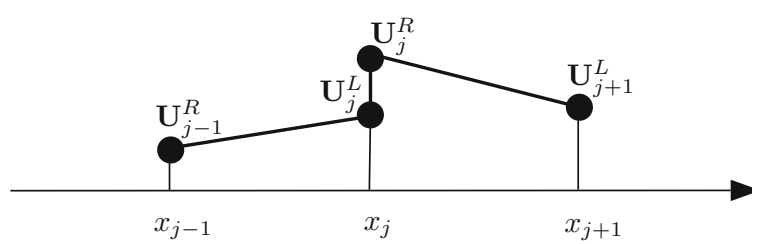

Fig. 7 Illustration of discontinuities at element boundaries in DG method

$$
N_{1}=\frac{x_{2}-x}{x_{2}-x_{1}}, \quad \mathrm{~N}_{2}=\frac{\mathrm{x}-\mathrm{x}_{1}}{\mathrm{x}_{2}-\mathrm{x}_{1}}
$$

In Eqs. 6 and 7, the flux terms are integrated by parts. The approximate variables $\hat{A}$ and $\hat{Q}$ as well as any function $\hat{f}$ are given by:

$\hat{A}=N_{j} A_{j}, \quad \hat{Q}=N_{j} Q_{j}, \quad \hat{f}(A, Q, n)=f(\hat{A}, \hat{Q}, \hat{n})$

where $N_{j}(j=1,2)$ are linear shape or interpolating functions taken to be the same as test functions in the Galerkin method.

The water surface gradient term on the right-hand side of Eq. 7 is discretized using the following expression (see Fig. 7)

$$
\begin{aligned}
& -g N_{1} \hat{A} \frac{\partial \hat{Z}}{\partial x}=-g N_{1} \frac{\left(A_{x_{1}}^{L}+A_{x_{2}}^{L}\right)}{2} \frac{\left(Z_{x_{2}}^{L}-Z_{x_{1}}^{L}\right)}{\left(x_{2}-x_{1}\right)} \\
& -g N_{2} \hat{A} \frac{\partial \hat{Z}}{\partial x}=-g N_{2} \frac{\left(A_{x_{1}}^{R}+A_{x_{2}}^{R}\right)}{2} \frac{\left(Z_{x_{2}}^{R}-Z_{x_{1}}^{R}\right)}{\left(x_{2}-x_{1}\right)}
\end{aligned}
$$

in which $A_{x_{i}}^{L}$ and $A_{x_{i}}^{R}$ are the values of $A$ at boundary $x_{i}$ from the left and right elements.

The friction term in Eq. 7 is discretized using a standard finite element method.

(ii) Numerical flux and wetting and drying: In order to calculate the flux functions $(E$ and $G$ ) at the element boundaries, an approximate Harten Lax and van Leer (HLL) Riemann solver (Toro et al. 1994) is implemented and is given by

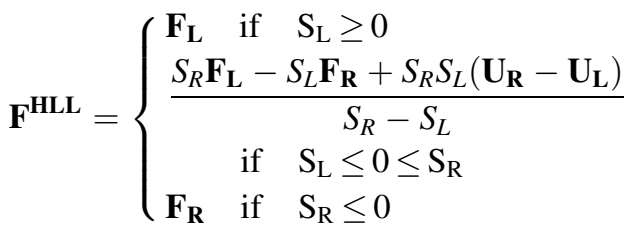

where subscripts $L$ and $R$ stand for the left-hand side and right-hand side of a node respectively. The wave speeds on the left $S_{L}$ and right $S_{R}$ sides of a boundary are defined by

$$
\begin{aligned}
& S_{L}=\min \left(u_{L}-c_{L}, \mathrm{u}^{*}-\mathrm{c}^{*}\right) \\
& S_{R}=\max \left(u_{R}+c_{R}, \mathrm{u}^{*}+\mathrm{c}^{*}\right)
\end{aligned}
$$

and

$$
\begin{aligned}
& u^{*}=0.5\left(u_{L}+u_{R}\right)+c_{L}-c_{R} \\
& c^{*}=0.5\left(c_{L}+c_{R}\right)+0.25\left(u_{L}-u_{R}\right)
\end{aligned}
$$


where $u=Q / A$ is the cross-sectionally averaged longitudinal velocity, $c=\sqrt{g A / b}$ is the celerity and $b$ is the width of the channel at the water surface.

For an initially dry bed, a sufficiently small depth, $h_{d r y}$, and zero velocity are defined at the dry nodes (Ying et al. 2004). After every time step, the whole domain is checked for the water depth; if the water depth at a node is less than $h_{d r y}$ it is set to $h_{d r y}$ and the flow rate is set to zero. The wave speeds on the left $\left(S_{L}\right)$ and right $\left(S_{R}\right)$ sides are modified in case of partially wet elements. For the dry on the right side of a node, i.e., $h_{L}>0$ and $h_{R}=0$, the wave speeds are calculated using Eq. 16. Equation 17 is used when the dry bed exists on the left side of a node, i.e., $h_{L}=0$ and $h_{R}>0$.

$S_{L}=u_{L}-c_{L} ; S_{\mathrm{R}}=\mathrm{u}_{\mathrm{L}}+2 \mathrm{c}_{\mathrm{L}}$

$S_{L}=u_{R}-2 c_{R} ; \mathrm{S}_{\mathrm{R}}=\mathrm{u}_{\mathrm{R}}+\mathrm{c}_{\mathrm{R}}$

If the water depth on both sides of a boundary is less than or equal to $h_{d r y}$, the numerical flux in Eq. 11 will be zero because the flow rate is zero, so the mass and momentum flux will be conserved. This approach always ensure a positive water depth and dry elements can be evaluated accurately (Lai and Khan 2012).

(iii) Runge-Kutta TVD Time integration: Equations 6 and 7 can be written in the following form after numerical integration

$$
\frac{\partial \mathbf{U}}{\partial t}=L(\mathbf{U})
$$

To advance the solution from time step $n$ to $n+1$, the second-order TVD Runge-Kutta scheme, as given by Gottlieb and Shu (1998), can be written as

$$
\left\{\begin{array}{l}
\mathbf{U}^{[\mathbf{1}]}=\mathbf{U}^{\mathbf{n}}+\Delta t L\left(\mathbf{U}^{\mathbf{n}}\right) \\
\mathbf{U}^{\mathbf{n}+\mathbf{1}}=\frac{1}{2} \mathbf{U}^{\mathbf{n}}+\frac{1}{2} \mathbf{U}^{[\mathbf{1}]}+\frac{1}{2} \Delta t L\left(\mathbf{U}^{[\mathbf{1}]}\right)
\end{array}\right.
$$

For the explicit scheme adopted here, the CFL (CourantFriedrichs-Lewy) condition must be fulfilled and is given by

$$
\max \left[\frac{\Delta t}{\Delta x}(|u|+c)\right] \leq \frac{1}{2 p+1}
$$

in which $p$ is order of polynomial used for space discretization (Cockburn 1999).

(iv) Slope limiting Procedure: Slope or flux limiters are required to suppress spurious oscillations near steep gradients and discontinuities. The slope limiter in a general form for a variable $\phi$ in an element, $l$, can be written as

$$
\phi_{l}(x)=\bar{\phi}_{l}+\left(x-\bar{x}_{l}\right) \sigma_{l} ; x_{1} \leq x \leq x_{2}
$$

The variable $\phi$ can be the water surface, $Z$, the cross section flow area, $A$, or flow rate, $Q . \bar{\phi}_{l}$ is the average value of a variable over an element, $l$, and $\bar{x}_{l}$ is the midpoint of the element. A monotonized central slope limiter ( $\mathrm{Li} 2006)$ is used and for an element $l$, it can be written as

$$
\sigma_{l}=\frac{[\operatorname{sign}(\alpha)+\operatorname{sign}(\beta)]}{2} \min \left(\frac{|\alpha+\beta|}{2}, 2|\alpha|, 2|\beta|\right)
$$

The upwind slope $\alpha$, the downwind slope $\beta$ are, respectively, given by

$$
\begin{aligned}
& \alpha=\frac{\bar{\phi}_{l}-\bar{\phi}_{l-1}}{\bar{x}_{l}-\bar{x}_{l-1}} \\
& \beta=\frac{\bar{\phi}_{l+1}-\bar{\phi}_{l}}{\bar{x}_{l+1}-\bar{x}_{l}}
\end{aligned}
$$

\section{Simulations and results}

The reach used in this investigation was located between Sidi Ali Benyoub and Sidi Bel Abbes gauging stations over $52 \mathrm{~km}$ of a routing distance. The basic data requirements include details of the effective bed profile, channel crosssections and hydraulic resistance characteristics of the Wadi.

Figure 8 shows the effective bed profile obtained from the 1:100,000 scale maps by identifying locations where the topographic contours intersected the river channel. Some measured cross-sections, shown as straight lines across the Wadi, are shown in Fig. 9. Figure 10 shows the measured cross-sections at Sidi Ali Banyoub gauging station and in the center of Sidi Bel Abbes town. The crosssections used in the computation are interpolated from the available data. The channel resistance, represented by Manning's coefficient $(n)$, represent a composite roughness of the channel and floodplain, including the effects of storage associated with floodplain inundation (Atallah and Hazzab 2013). Table 4 presents Manning's $n$ values used in the various subreaches of Wadi Mekerra.

The events used in this analysis were the 1983 summer flood and 1995 autumn flood on the Wadi Mekerra. In this investigation, lateral inflows along the study reach were neglected. A dry bed was assumed as an initial condition for simulation. The hourly discharge measured at Sidi Ali Benyoub gauging station is used as the inflow boundary condition, while the hourly discharge measured at Sidi Bel Abbes gauging station provided a means of assessing the model performance.

Figure 11 illustrates the upstream boundary condition used for flood occurred in June 24, 1983. The maximum discharge recorded during this event was $100 \mathrm{~m}^{3} / \mathrm{s}$. The simulation results are presented in the same figure for $t=47 \mathrm{~h}$. The flood peak predicted by the model was $7.36 \mathrm{~m}^{3} / \mathrm{s}$ higher than the measured peak flow rate $\left(53.8 \mathrm{~m}^{3} / \mathrm{s}\right.$ ). The timing of the peak arrival (for the 
measured and computed hydrographs) is quite accurate. In this case the peaks arrives in the same time; i.e. $6 \mathrm{~h}$ after the peak observed at Sidi Ali Benyoub.

Figure 12 illustrates the upstream boundary condition used for the flood occurred in October 11, 1995. The

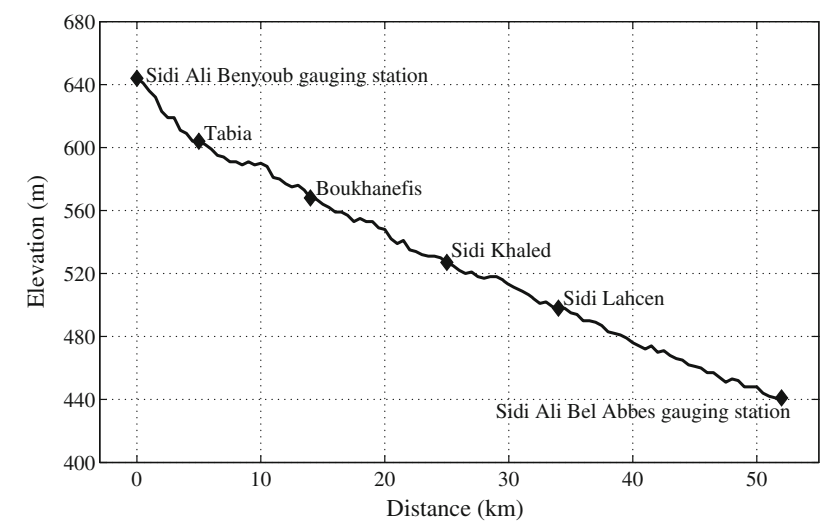

Fig. 8 Profile of the Wadi Mekerra between Sidi Ali Benyoub and Sidi Bel Abbes gauging stations maximum discharge recorded during this event was $155 \mathrm{~m}^{3} / \mathrm{s}$. The results are presented in the same figure for $t=47 \mathrm{~h}$. The results of the simulation were compared subsequently with the hydrograph at the station in Sidi Bel Abbes (output) where the measured peak flow rate was $116 \mathrm{~m}^{3} / \mathrm{s}$. The results shows that the simulated hydrograph was very close to that registered in the Sidi Bel Abbes gauge station. The same results indicate a decrease of about $37.64 \mathrm{~m}^{3} / \mathrm{s}$ in the maximum flow discharge value between the extreme nodes. The time required for the wave to reach the station in Sidi Bel Abbes was 7 hours. The difference between the two hydrographs (simulated and measured) was about $1.17 \%$ in the flow discharge.

For the two events we observe that the simulated flow discharges were greater than the measured flow discharge at Sidi Bel Abbes gauge station (Table 5). The difference can be due to the natural regularization of flow rate in phase of fall which can be justified by the formation of a multitude of extended spreading characteristics to the particular topography of the area. The geomorphological, geological and lithological properties of the catchment

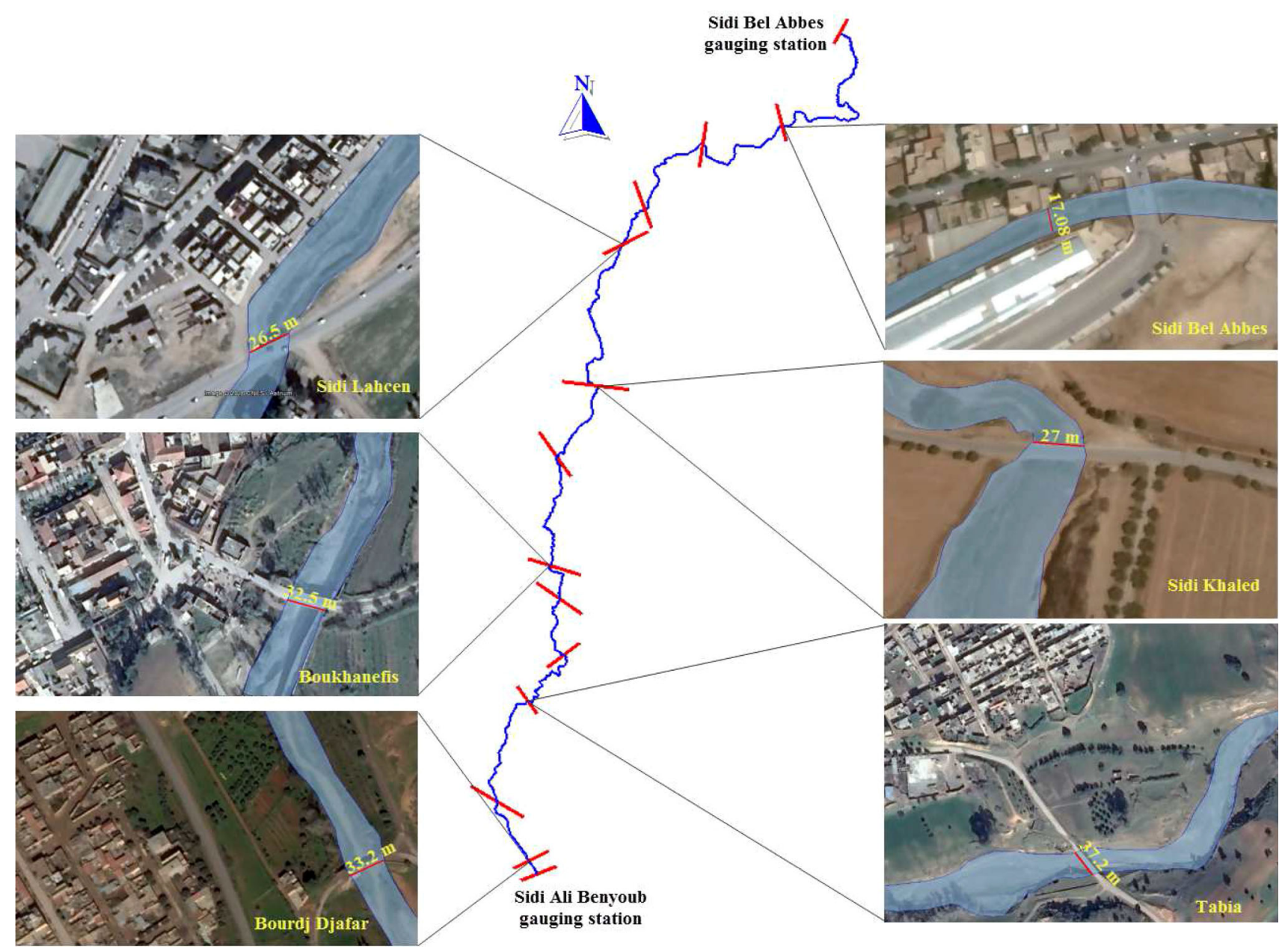

Fig. 9 Map of the studied reach and the location of some computational cross-sections 

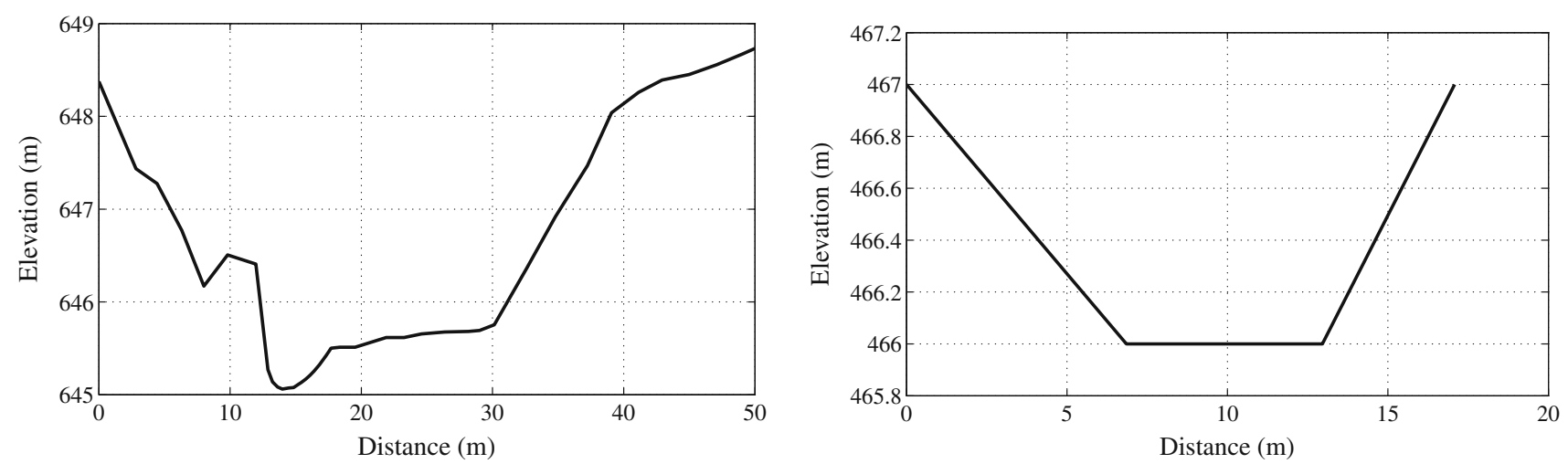

Fig. 10 Measured cross-sections at Sidi Ali Banyoub gauging station (left plot) and in the center of Sidi Bel Abbes town (right plot)

Table 4 Selected Manning's $n$ values for the Wadi Mekerra reach (Atallah and Hazzab 2013)

\begin{tabular}{llllll}
\hline Location $(\mathrm{km})$ & $0-13$ & $13-22$ & $22-32$ & $32-41$ & $41-52$ \\
\hline Manning's $n$ & 0.040 & 0.100 & 0.035 & 0.030 & 0.010
\end{tabular}

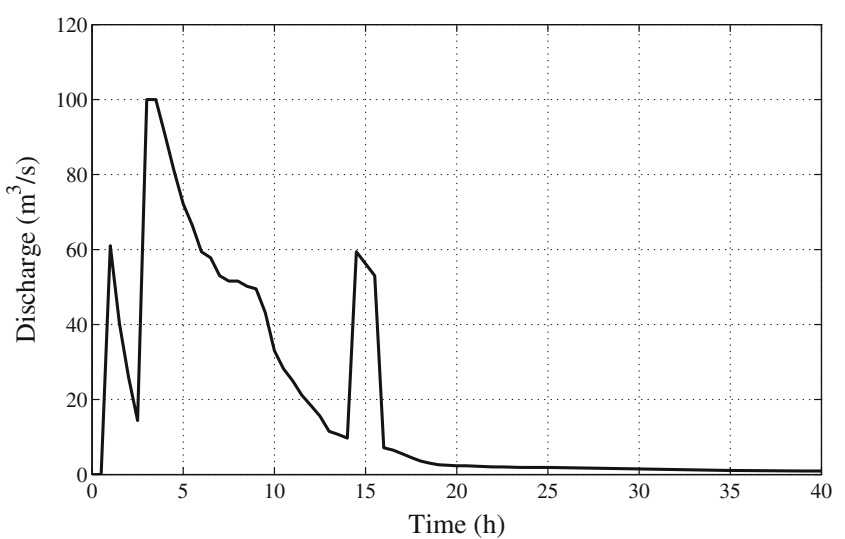

area located between Sidi Ali Benyoub and Sidi Bel Abbes significantly contribute to regularize the flow rate, and to reduce flood levels. However, transmission losses from flood hydrograph through bed infiltration are important factors in reducing the flood, and obscure the interpretation of observed hydrographs at Sidi Bel Abbes gauging station.

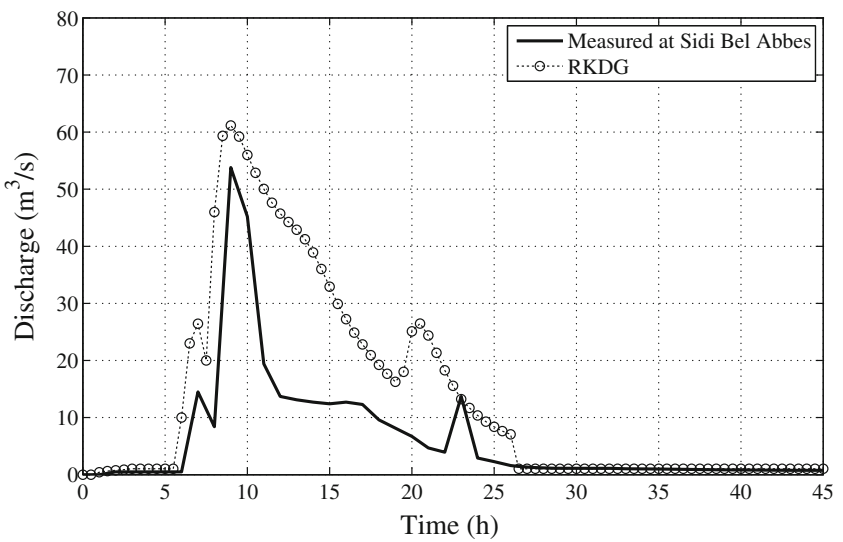

Fig. 111983 summer flood event: Hydrographs measured at Sidi Ali Benyoub (left plot) and comparison of measured and computed water discharges at Sidi Bel Abbes gauging station (right plot)
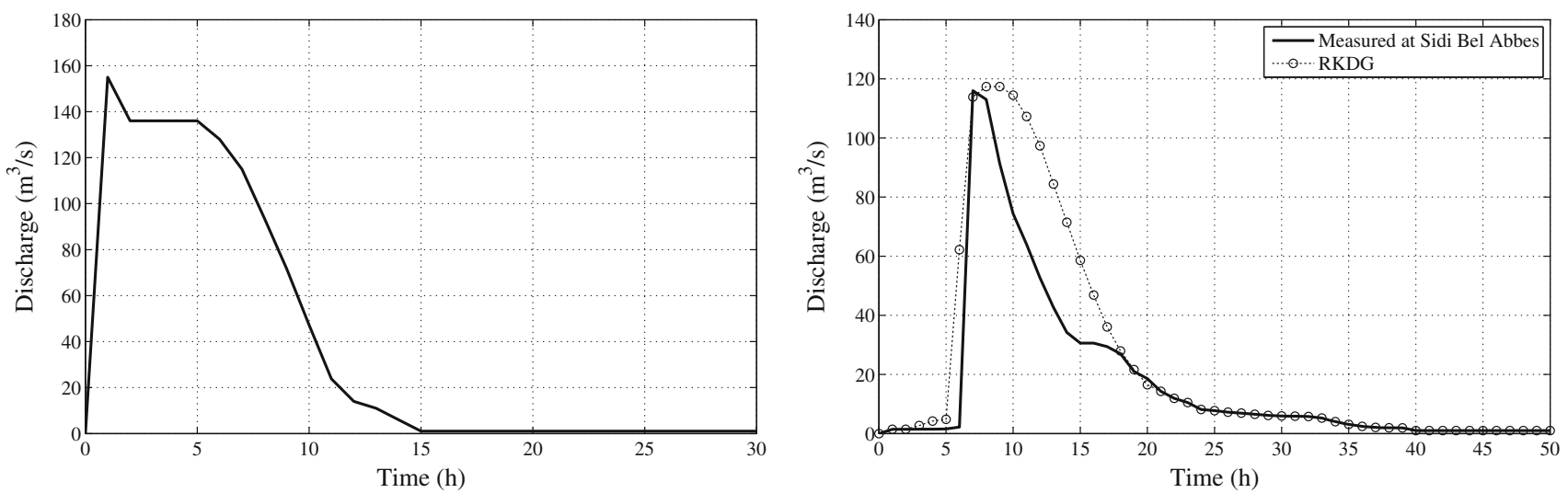

Fig. 121995 autumn flood event: Hydrographs measured at Sidi Ali Benyoub (left plot) and comparison of measured and computed water discharges at Sidi Bel Abbes gauging station (right plot) 
Table 5 Comparison of peak discharge accuracy for the two eventscase 1: 1983 summer flood; case 2: 1995 autumn flood

\begin{tabular}{lll}
\hline Hydrograph & Case 1 & Case 2 \\
\hline Measured at Sidi Ali Benyoub & 100.00 & 155.00 \\
Computed at Sidi Bel Abbes & 61.16 & 117.36 \\
Measured at Sidi Bel Abbes & 53.80 & 116.00 \\
\hline
\end{tabular}

This infiltration was increased by the presence of the faults directed from the South to the centre of the catchment area (Atallah and Hazzab 2013).

\section{Conclusion}

Wadi Mekerra, located in the North-West of Algeria in a semi-arid zone, is an ephemeral watercourse. Catastrophic flash floods occurring in this wadis are a threat to twenty five agglomerations. Flood, in this region, is caused by heavy or excessive rainfall in a short period of time particularly in the beginning of autumn.

In this paper we have presented a modeling approach which uses unsteady flow hydraulic model for semiarid flash flood forecasting. The one-dimensional model based on the SaintVenant equations was solved by a Runge-Kutta Discontinuous Galerkin finite element scheme. The mass and momentum flux terms are evaluated by HLL flux function. The model uses a linear element for the spatial discretization and a second-order TVD Runge-Kutta scheme to advance in time. In addition, a simple technique is adopted to simulate the movement of wet/dry fronts. We have applied the method for simulation of flood propagation in Wadi Mekerra. A comparison between the measured and simulated results showed that the model used is appropriate for determining the flood hydrograph at the outlet of the watercourse.

The current RKDG scheme can be straightforwardly extended to free surface flows in two space dimensions. It will make it possible to determine flooding extent, depth, level and velocity that can be all mapped. Geographic information system (GIS) and remote sensing applications can help to extract data inputs to the numerical model. These and further issues are subject of future investigations.

\section{References}

Abbott MB, Refsgaard JC (1996) Distributed hydrologic modeling. Kluwer Academic Publishers, London

Argyroudi A, Chatzinikolaou Y, Poirazidis K, Lazaridou M (2009) Do intermittent and ephemeral Mediterranean rivers belong to the same river type? Aquat Ecol 43(2):465-476. doi:10.1007/ s10452-008-9176-9
Arora V, Seglenieks F, Kouwen N, Soulis E (2001) Scaling aspects of river flow routing. Hydrol Process 15(3):461-477. doi:10.1002/ hyp. 161

Atallah M, Hazzab A (2013) A Petrov-Galerkin scheme for modeling 1D channel flow with varying width and topography. Acta Mech 224(4):707-725. doi:10.1007/s00707-012-0781-2

Bathurst JC (1988) Flow processes and data provision for channel flow models. In: Anderson MG (ed) Modelling geomorphological systems. Wiley, Chichester, pp 127-152

Blackburn J, Hicks F (2002) Combined flood routing and flood level forecasting. Can J Civ Eng 29(1):64-75. doi:10.1139/101-079

Chaudhry MH (2008) Open-channel flow. Springer Science \& Business Media, New York

Choudhury P, Shrivastava RK, Narulkar SM (2002) Flood routing in river networks using equivalent Muskingum inflow. J Hydrol Eng 7(6):413-419. doi:10.1061/(ASCE)1084-0699(2002)7: $6(413)$

Chow VT (1959) Open channel hydraulics. McGraw-Hill Book Company, Inc, New York

Cockburn B (1999) Discontinuous Galerkin methods for convectiondominated problems. In: Barth TJ, Deconinck H (eds) Highorder methods for computational physics, Lecture Notes in Computational Science and Engineering, vol 9. Springer, Berlin, Heidelberg, pp 69-224. doi:10.1007/978-3-662-03882-6_2

Ernst J, Dewals BJ, Detrembleur S, Archambeau P, Erpicum S, Pirotton M (2010) Micro-scale flood risk analysis based on detailed 2D hydraulic modelling and high resolution geographic data. Nat Hazards 55(2):181-209. doi:10.1007/s11069-0109520-y

Gottlieb S, Shu CW (1998) Total variation diminishing Runge-Kutta schemes. Math Comput 67(221):73-85. doi:10.1090/S00255718-98-00913-2

Hanson S, Nicholls R, Ranger N, Hallegatte S, Corfee-Morlot J, Herweijer C, Chateau J (2011) A global ranking of port cities with high exposure to climate extremes. Clim Change 104(1):89-111. doi:10.1007/s10584-010-9977-4

Henderson F (1966) Open-channel flow. MacMillan Publishing Co., New York

Hervouet JM (2007) Hydrodynamics of free surface flows: modelling with the finite element method. Wiley, Chichester

Hicks FE (1996) Hydraulic flood routing with minimal channel data: Peace River, Canada. Can J Civ Eng 23(2):524-535. doi:10. 1139/196-057

Isaacson E, Stoker JJ, Troesch BA (1954) Numerical solution of flood prediction and river regulation problems (Ohio-Mississippi floods). Report II $\mathrm{N}^{\circ}$ IMM-NYU-205, New York University, Institute of Mathematical Sciences

Khan AA, Lai W (2014) Modeling shallow water flows using the discontinuous Galerkin method. Taylor \& Francis Group, CRC Press, Boca Raton

Korichi K, Hazzab A (2012) Hydrodynamic investigation and numerical simulation of intermittent and ephemeral flows in semi-arid Regions: Wadi Mekerra, Algeria. J Hydrol Hydromech 60(2):125-142. doi:10.2478/v10098-012-0011-6

Lai W, Khan AA (2012) Discontinuous Galerkin method for 1d shallow water flows in natural rivers. Eng Appl Comput Fluid Mech 6(1):74-86. doi:10.1080/19942060.2012.11015404

Lettenmaier DL, Wood EF (1993) Hydrologic forecasting. In: Maidment DR (ed) Handbook of hydrology. McGraw-Hill Inc, New York

LeVeque RJ (2002) Finite volume methods for hyperbolic problems. Cambridge University Press, Cambridge

Li BQ (2006) Discontinuous finite elements in fluid dynamics and heat transfer. Springer, London

Liggett JA, Cunge JA (1975) Basic equations of unsteady flow. In: Mahmood K, Yevjevick V (eds) Unsteady flow in open channels, 
vol 1, chap 2. Water Resources Publications, Fort Collins, pp 29-62

Llasat M, Llasat-Botija M, Rodriguez A, Lindbergh S (2010) Flash floods in Catalonia: a recurrent situation. Adv Geosci 26:105-111. doi:10.5194/adgeo-26-105-2010

Matthews WJ (1988) North American prairie streams as systems for ecological study. J North Am Benthol Soc, pp 387-409. doi:10. 2307/1467298

McKay K, Mikolajczyk S, Hicks F (1996) Application of hydraulic flood routing techniques to the 1995 flood in Southern Alberta. In: Proceedings of the CSCE Annual Conference. Edmonton, Alta, pp 132-142

Meddi M, Toumi S (2015) Spatial variability and cartography of maximum annual daily rainfall under different return periods in Northern Algeria. J Mt Sci 12(6):1403-1421. doi:10.1007/ s11629-014-3084-3

Merz B, Kreibich H, Schwarze R, Thieken A (2010) Review article "Assessment of economic flood damage". Nat Hazards Earth Syst Sci 10(8):1697-1724. doi:10.5194/nhess-10-1697-2010

Perumal M, Moramarco T, Melone F (2007) A caution about the multilinear discrete lag-cascade model for flood routing. J Hydrol 338(3):308-314. doi:10.1016/j.jhydrol.2007.02.022

Preissmann A (1961) Propagation des intumescences dans les canaux et rivières. In: 1st Congress of the French Association for Computation, Grenoble, pp 433-442

Price C, Yair Y, Mugnai A, Lagouvardos K, Llasat M, Michaelides S, Dayan U, Dietrich S, Di Paola F, Galanti E et al (2011) Using lightning data to better understand and predict flash floods in the Mediterranean. Surv Geophys 32(6):733-751. doi:10.1007/ s10712-011-9146-y

Sardou M, Maouche S, Missoum H (2016) Compilation of historical floods catalog of northwestern Algeria: first step towards an atlas of extreme floods. Arab J Geosci 9(6):1-15. doi:10.1007/s12517016-2490-y

Schubert JE, Sanders BF (2012) Building treatments for urban flood inundation models and implications for predictive skill and modeling efficiency. Adv Water Resour 41:49-64. doi:10.1016/j. advwatres.2012.02.012
Şen Z (2008) Wadi hydrology. Taylor \& Francis Group, CRC Press, Boca Raton

Shaw EM, Beven KJ, Chappell NA, Lamb R (2010) Hydrology in practice. CRC Press, Boca Raton

Singh VP (1988) Hydrologic systems, vol 1: Rainfall-runoff medeling. Prentice-Hall, Inc., Englewood Cliffs

Singh VP (1989) Hydrologic systems, vol 2: Watershed medeling. Prentice-Hall, Inc., Englewood Cliffs

Smithers JC, Caldecott RE (1995) Hydrograph routing. In: Schulze RE (ed) Hydrology and agrohydrology: a text to accompany the ACRU 3.00 Agrohydrological Modelling System, TT 69/95, Water Research Commission, Pretoria, pp AT13-1-AT13-16

Stoker JJ, Isaacson E, Troesch A (1953) Numerical solution of flood prediction and river regulation problems I, Derivation of basic theory and formulation of numerical methods of attack. Report $\mathrm{N}^{\circ}$ IMM-200, New York University, Institute of Mathematical Sciences

Toro EF, Spruce M, Speares W (1994) Restoration of the contact surface in the HLL-Riemann solver. Shock Waves 4(1):25-34. doi:10.1007/BF01414629

Uys MC, O'keeffe JH, (1997) Simple words and fuzzy zones: Early directions for temporary river research in South Africa. Environ Manag 21(4):517-531. doi:10.1007/s002679900047

Viessman W, Lewis GL, Knapp JW (1989) Introduction to hydrology. Harper and Row Publishers, Inc., New York

Wilson EM (1990) Engineering hydrology. Macmillan, Indianapolis, pp 110, 196, and 301

Yamani K, Hazzab A, Sekkoum M, Slimane T (2016) Mapping of vulnerability of flooded area in arid region. Case study: area of Ghardaïa-Algeria. Model Earth Syst Environ 2(3):147. doi:10. 1007/s40808-016-0183-x

Ying X, Khan AA, Wang SS (2004) Upwind conservative scheme for the Saint Venant equations. J Hydraul Eng 130(10):977-987. doi:10.1061/(ASCE)0733-9429(2004)130:10(977) 